\title{
Evaluation of Corporate Social Responsibility Performance in Air Transport Enterprise
}

\author{
Dimitrios J. Dimitriou \\ Professor Associate, Department of Economics \\ Democritus University of Thrace, Panepistimioupolis Komotini, Greece, 69100 \\ E-mail: ddimitri@econ.duth.gr
}

Received: Mar. 10, 2020 Accepted: May 18, 2020 Online published: June 2, 2020

doi:10.5296/jpag.v10i2.16645 URL: https://doi.org/10.5296/jpag.v10i2.16645

\begin{abstract}
The key objective of this paper is to present the dimensions and the characteristics of an airport enterprise management engagement in Corporate Social Responsibility (CSR). By analyzing different strategies and plans towards CSR, applied in a sample of 15 European airports, the comprehensiveness is defined, providing the assessment framework of the airports CSR effectiveness and efficiency. Conventional wisdom is to provide a CSR assessment framework applied on airport industry. The methodology based on the competitive analysis framework, driven by benchmarking analysis applied to a group of European airports engaged in different CSR strategies. Defining the key actions of the airports CSR strategy, an assessment framework to review how this strategy meets social goals is developed. The airport strategy is reviewed considering the aviation business characteristics such as, traffic and regional GDP. Based on data collected from 15 busy European airports, the comprehensiveness of CSR strategy for this business sector considering stakeholders' theory is investigated. The outputs provide key messages to decision makers, managers, and stakeholders towards CSR comprehensiveness of the airport operators.
\end{abstract}

Keywords: corporate social responsibility, corporate sustainability, social comprehensiveness performance, stakeholder theory, CSR strategy, stakeholders, airport enterprise management

\section{Introduction}

Aviation sector despite the economic crises signs during last years, has demonstrated long-term resilience, Historically, air transport has doubled in size every fifteen years and has grown faster than most other industries. In 2018, airlines worldwide carried around 4.3 billion passengers annually with 8.3 trillion revenue passenger kilometres (RPKs). Fifty-eight 
million tonnes of freight were transported by air, reaching 231 billion freight tonne kilometres (FTKs). Every day, more than 100,000 flights transport almost 12 million passengers and around USD 18 billion worth of goods, according to latest estimates (ACI et al., 2019).

This growth influenced airport stakeholders and airport enterprise management through economic, social, and environmental dimensions. This rapid growth has raised serious concerns of community members and local and state agencies and authorities as regards the associated social and environmental impacts of airlines and airport operations. Air transportation infrastructures, like other critical infrastructures, has enormous impact on local, national, and international economies. That means that airports not only are being developed, benefited, and benefit the environment that have business activity, but also have environmental and societal aggravating reaction. For this reason, is important the adoption of the Triple Bottom Line concept, in order airports have a balanced presence in society.

Therefore, due to the significant socio-economic and environmental impacts airport enteprises management focus on sustainable development as a response to the pressure received by their various stakeholders. An enterprise's strategic decision is affected by external factors and dimensions. Therefore, enteprises management focus not only on market pressures, but also to institutional pressures from regulatory authorities, governmental bodies, and society.

Under this pressure from internal and external stakeholders, airport enteprises consider a variety of sustainability initiatives according to environmental and social impacts of airports enterprise management. In question to this, airport enteprises Corporate Social Responsibility (CSR) address the actions and measures have adopted by airports to reach the above targets and adapt a more socially responsible approach to their stakeholders.

In literature the relationship between sustainable development and, CSR and innovation, with emphasis on sustainable development in business driven by innovation is analyzed (Klewitz et al., 2014). Several researches have focused on the key elements of corporate social responsibility (Arguinis et al., 2012, Marin et al., 2017), especially, focusing on the factors of responsible innovation (Neumeier, 2017, Zhao et al., 2019, Bocquet et al., 2017), but few of them have analyzed the dimension of corporate social responsibility on the competitiveness (Herrera et al., 2015).

Management literature uses both CSR and CS to refer to social and environmental management issues, but there is no clear distinction between these two terms. Yet the word "sustainability" remains ambiguous. In the past, while corporate responsibility referred to social aspects such as human rights, sustainability was usually related to the environment. In addition, despite the traditional bias of corporate sustainability towards environmental policies, there is interest in integrating social and economic aspects into corporate sustainability (Sartzetaki, 2019).). Although nowadays it is widely accepted that CSR and CS approaches have similar conceptualizations of economic, social, and environmental dimensions, there is a difference, lying on the hierarchical relationship between CSR and CS. Corporate social responsibility is describes aa the necessity and the duty of an entity to 
behave responsibly, ethically and sustainably and to be transparently accountable to its stakeholders (Sartzetaki, 2019). Therefore, sustainability and consequently Corporate Sustainability placed as the goal, with CSR as an intermediate stage where companies try to balance the Triple Bottom Line.

Additionally, the proposal by Lassi Linnanen and Virgilio Panapanaan implies a distinct disaggregation of dimensions - distinguishing sustainability from responsibility - to draw a more consistent picture. The three aspects of sustainability (economic, environmental, and social) can be translated into an approach that encloses the responsibilities that companies must be concerned with. The clear relationship between CS and CSR based on this approach shows the hierarchical relationship that distinguishes these terms. Conclusion can be drawn by the relation between CSR and CS is that i) Corporate Social Responsibility is related with how the company has integrated perception of its position in society through a balanced relationship with the 3Ps concept and ii) Corporate Sustainability, as being the ultimate goal for the company, is related with the long-term planning, the goals and the vision that a company has for its sustainable development in the future.

Stakeholder integration refers to partnerships where organizational stakeholders such as customers, communities and suppliers inform organizational practices to deliver improved performance (Desai, 2018). In addition, that stakeholder integration can stimulate economic and financial performance by prompting organizations to engage in environmental sustainability orientation (Li, Xia, \& Zajac, 2018).

As indicated by De Gooyert, Rouwette, van Kranenburg, \& Freeman, 2017, the concept of 'stakeholder multiplicity', may stress that enterprise management must acknowledge stakeholders as part of a network. A gap on literature on the analyzing that stress in airport enterprise management is highlighted in the paper.

Despite the growing research on the influence of stakeholder integration on organizational outcomes, a deeply analysis of the specific airport enterprise conditions that may mediate the relationship between stakeholder integration and airport performance is lacking.

In this paper, by investigating CSR reports from European airport industry and assorting actions and measures that specify socially responsible actions and measures, a CSR assessment tool suggested in order to determine CSR reports' comprehensiveness in quantitative data considering stakeholder's theory is applied. It is highlighted how airport industry go about their CSR strategies. As airports are the most significant elements of the air transportation industry the indicators for the CSR of airport enteprises management addresses the airport sustainable development among all relevant stakeholders.

This paper is structured as follows. After the introduction, the second part presents the theoretical background and the hypotheses development. Then the analysis research method and findings are presented. The conclusion section focuses on the implications of the results as well as the limitations of the study and direction for future research. 


\section{Theoretical Background and Hypothesis}

\subsection{Stakeholder Orientation Theory Review}

In order to improve sustainable development, enteprises must integrate a CSR approach in their strategic planning and management (Dimitriou et al., 2020). The incorporation of CSR in strategic planning has as a goal companies' corporate sustainability which is inextricably tied with a company's long-term success. For been this achieved, managers need to define their company's stakeholders (shareholders, employees, customers, suppliers, community etc) and understand their concerns, to develop objectives that stakeholders would support (Dimitriou et al., 2016; Galbreath, 2006). This support is necessary for long term success. Therefore, management should actively explore its relationships with all stakeholders to develop business strategies (in a sustainable framework (Dimitriou et al., 2019).

Therefore, by taking the strategic approach of CSR development, companies can determine what activities they have the resources to devote to being socially responsible and can choose that which will strengthen their competitive advantage. By planning out CSR as part of a company's overall plan, organizations can ensure that profits and increasing shareholder value don't overshadow the need to behave ethically to their stakeholders. Strategic CSR provides companies with solutions for balancing the creating of economic value with that of societal value, managing their stakeholder relations, especially those with competing values and identifying and responding to threats and opportunities facing their stakeholders. As a result of strategic CSR, companies develop sustainable business practices and espouse sustainable decision-making (Dimitriou, 2018).

The basic tenet of the stakeholder theory suggests that stakeholders are critical for a firm's success as they affect the firm's long-term strategic goals. Moreover, conflicts of interest between managers and stakeholders or among the stakeholders themselves may exist to blur the definition and roles (Eskerod et al., 2015). An analytical description of the key different stakeholder involved in this long-term strategic goals determination process is depicted in Figure 1.

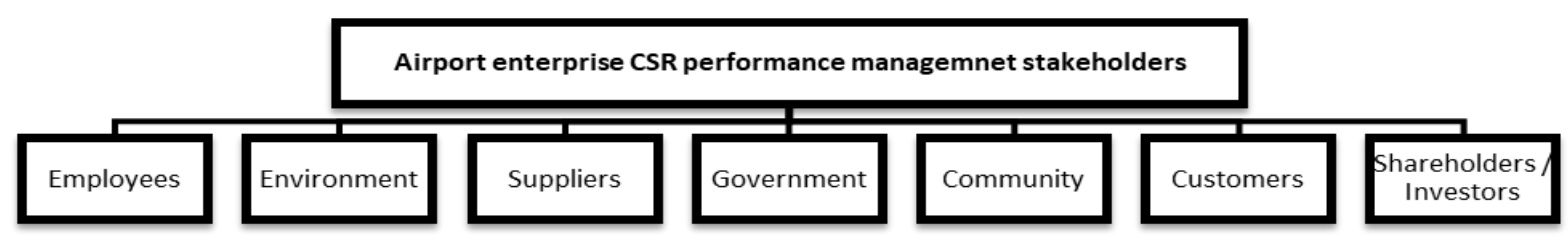

Figure 1. Airport enterprise CSR performance stakeholders

On the other side, Carroll's Pyramid of Corporate Social Responsibility encompasses the economic, legal, ethical and discretionary expectations that society has of organizations. Just as society expects business to make a profit (as an incentive and reward) for its efficiency and effectiveness, society expects business to obey the law. Society expects business to fulfill its economic mission within legal system. The next two responsibilities represented in order to specify the kind or nature of the responsibilities that extend beyond obedience to the law. The ethical responsibility represents the kinds of behaviors and ethical norms that society expects 
business to follow. These extend to behaviors and practices that are beyond what is required by the law. Finally, there are discretionary responsibilities. These responsibilities represent voluntary roles that business assumes but for which society does not provide as clear-cut an expectation as it does in the ethical responsibility. They are left to individual managers' and corporations' judgment and choice; however, the expectation that business performs these still exists. This expectation is driven by social norms. The specific activities are guided by businesses' desire to engage in social roles not mandated or required by law and not expected of businesses in an ethical sense, but which are increasingly strategic.

By the side of airports, we can clearly fit the CSR concept on how airports should realize their role considering Social Responsibility by taking into consideration their reaction with their internal and external stakeholders. The rapid growth influenced airport stakeholders incredibly through economic, social and environmental dimensions. This growth adversely affects the environment; increases energy and fuel consumption that releases greenhouse gases into the environment which causes the climate change, also generates significant solid and water wastes, and increases air and noise pollution (Montiel, 2008). The airport infrastructure which cannot be developed simultaneous due to the growth rate, will let flight delays, delivering incorrect baggage, presenting low service quality, causing dissatisfied customers. Building extra airport units like terminal and runways in order to avoid these problems will increase negative environmental impacts. On the other hand, there are positive contributions like creating job opportunities, providing fast and secure transportation, rising incomes and the support of tourism influences social and economic life (Koç, S., \& Durmaz, V. (2015). Due to the significant socio-economic and environmental impacts inherent to their operations, what can arise as general view about how airports, adopting the CSR concept, can have a sustainable presence in society is that they should be profitable, obey the law, be ethical and therefore be a good citizen respecting and fulfilling all these conditions considering their stakeholders including shareholders and environment (Aarseth et al., 2011)

\subsection{Business Case for Sustainability Based on Corporate Shared Value}

Vveinhardt et al. (2014) concluded that social responsibility in the field of social capital can be identified as a value of stakeholders' moral and material capital, created through mutual trust, which should be expanded in the development of stakeholder trust and mutual commitment. In this context Creating Shared Value (CSV), as introduced by Michael Porter and Mark Kramer (2011), is arguably the leading approach for articulating the business case for corporate sustainability. The business case for corporate sustainability - often expressed in terms of "win-win" situation ( Pederson et al., 2017). According to Naor et al., 2018, CSV searches for win-wins that leverage corporate expertise and assets to address social and environmental issues in enterprise management.

While the reach of CSV goes beyond environmental issues to encompass societal concerns more broadly (Porter and Kramer, 2011), in this paper, we focus exclusively on the implications both for environmental and societal issues of our analysis on the domain of corporate sustainability based on stakeholders orientation. 


\section{Al Macrothink}

Journal of Public Administration and Governance

ISSN 2161-7104

2020, Vol. 10, No. 2

\section{CSR Actions Identification Based on Stakeholder Orientation in Airport Enterprises}

The stakeholder theory accentuates the notion that corporations must be viewed as operating at the center of a "network of interrelated stakeholders that create, sustain and enhance value creating capacity" In their assessment of CSR and CSP in the context of a sample of Italian SMEs, Longo et al. (2005) identified the demands of key stakeholders regarding the creation of value by the business, resulting in a grid of values, which associates each stakeholder with value classes that satisfy their respective expectations. These value classes have been derived based on studies and models already covered in existing literature, as well as based on the analysis of various social audit and sustainability reports. Companies in their study are considered as socially responsible if they demonstrate social behavior satisfying the expectations of at least half of the value classes identified for each stakeholder. In other words, these values constitute social goals that a company has to achieve in order to be characterized as socially responsible. The perspectives according to Longo et al., 2005, and the expectations for each perspective are:

P1. Employees

- Health and safety at work

- Development of workers' skills

- Wellbeing and satisfaction of worker

- Quality of work

- Social equity

P2. Suppliers

- Partnership between ordering company and supplier

- Selection and analysis systems of suppliers

P3. Customers

- Product quality

- Safety of customer during use of product

- Consumer protection

- Transparency of consumer product information

P4. Community

- Creation of added value to the community

- Environmental safety and production

From the airports' side, based on the above-mentioned researches, we defined at first through CSR and Sustainability reporting, as main stakeholders of airports the following: i) employees, ii) community or local community, iii) customers and iv) environment. The decision of these four stakeholders based primarily by a broad aspect according to Freeman's definition of stakeholder-"any group or individual who can affect or is affected by the achievement of the organization's objectives"(Dimitriou et al., 2018) (Then extended by a propose that classes of stakeholders can be identified by their possession or attributed possession of one, two, or all three of the following attributes: (1) the stakeholder's power to influence the firm, (2) the legitimacy of the stakeholder's relationship with the firm, and (3) the urgency of the stakeholder's claim on the firm. This theory produces a comprehensive typology of stakeholders based on the normative assumption that these variables define the 
field of stakeholders: those entities to whom managers should pay attention

What should be mentioned here is that environment diverted as stakeholder from community; to develop extensively this important dimension that has a vital role in airports' sustainable growth and strategic management. Furthermore, we determinate the actions that associated with each stakeholder, in order to create, as it is following extensively analyzed, a CSR comprehensiveness framework by the side of stakeholder theory approach.

\section{Methodology Framework}

The unit of analysis of this paper is Created Shared Value strategy framework based on stakeholder agent theory.

\subsection{Stakeholder Agent Theory Perspectives}

Taking into consideration the stakeholder theory and the view of applying this theory on the development of a corporate socially responsible strategy, a CSR comprehensiveness review on a sample of 15 of the busiest European airports structured. Through airports' Social Comprehensiveness Performance (SCP) in their four key stakeholders, the CSR strategy orientation considering stakeholders is defined in the extent of both quantitative and qualitative issues. Stakeholder theory chosen as it seems an appropriate base in collecting and analyzing CSR data as evidenced by the proliferation of empirical studies that have essentially integrated a stakeholder approach (Jamali D., 2008).

Furthermore, the four categories that represent airports' key stakeholders are separated in criteria and sub-criteria that include the societal aspects that define and best describe each category's social responsibility performance (Dimitriou, 2018).. Taking into consideration GRI guidelines, literature review and CSR and sustainability reporting, we conclude in the criteria that represent the values that associated with each stakeholder's expectations and included in each of four categories (Chao et al., 2019, Sartzetaki et al., 2019). Based on this, a framework of analysis, called as "ECCE framework" (by the first letter of Employees, Community, Customers, Environment) is structured (Table 1). In each criterion and sub-criterion, actions and measures categorized to assess the CSR comprehensiveness by the view of airports' stakeholders and define airports orientation that describes their CSR strategy approach.

Table 1. Stakeholders Perspectives and Criteria

\begin{tabular}{|c|c|c|}
\hline Stakeholder Perspectives & Criteria & Sub-criteria \\
\hline \multirow{5}{*}{ P1-Employees } & \multirow{5}{*}{$\begin{array}{l}\text { C1-Equal opportunities for employees / no } \\
\text { discrimination in work environment/ values } \\
\text { related to human rights }\end{array}$} & General (non-categorized) \\
\hline & & Skin color \\
\hline & & Ethnic (religion / nationality) \\
\hline & & Disable (because of illness, injury, senility) \\
\hline & & $\begin{array}{l}\text { Age discrimination (aged } 26 \text { or less, senior-aged and } \\
\text { over) }\end{array}$ \\
\hline
\end{tabular}




\begin{tabular}{|c|c|c|}
\hline & & $\begin{array}{l}\text { Work-life balance (maternity, paternity protection / } \\
\text { family-life protection with flexible work time etc / free } \\
\text { time support) }\end{array}$ \\
\hline & \multicolumn{2}{|l|}{ C2-Training - education } \\
\hline & \multirow[t]{2}{*}{ C3-Employment conditions } & General (non-categorized) \\
\hline & & Medical care / Additional pension / compensations \\
\hline & \multicolumn{2}{|c|}{$\begin{array}{l}\text { C4-Employees' participation in charity and activities related to social improvement (environment, } \\
\text { culture etc.) }\end{array}$} \\
\hline & \multicolumn{2}{|c|}{ C5-Open dialogue / Communication with employees } \\
\hline & \multicolumn{2}{|l|}{ C6-Health and safety } \\
\hline & \multicolumn{2}{|l|}{ C7-Addition support to employees } \\
\hline \multirow{10}{*}{ P2- Community } & \multicolumn{2}{|c|}{ C1-Donations, sponsorships (NGO, cultural events like sport, artistic etc.) and charity-Philanthropy } \\
\hline & C2-Education support & \\
\hline & \multirow{4}{*}{ C3-Actions against local unemployment } & Young unemployment \\
\hline & & Long-term unemployment \\
\hline & & Unemployment of people with disabilities \\
\hline & & General support against unemployment \\
\hline & \multicolumn{2}{|c|}{ C4-Dialogue-communication with local / Complaints' management } \\
\hline & \multicolumn{2}{|c|}{ C5-Quality of life support ("Green" local development) } \\
\hline & \multicolumn{2}{|c|}{ C6-Enhance economic development of local community } \\
\hline & \multicolumn{2}{|l|}{ C7-Additional support to locals (non-categorized) } \\
\hline \multirow[t]{7}{*}{ P3- Customers } & \multicolumn{2}{|c|}{ C1-Provision of services or facilities for families/kids } \\
\hline & \multicolumn{2}{|c|}{ C2-Provision of services or facilities for persons with special needs } \\
\hline & \multicolumn{2}{|c|}{ C3-Provision of services or facilities with respect to religion beliefs and nationality-language-culture } \\
\hline & \multicolumn{2}{|c|}{ C4-Complain management /customers' opinion share } \\
\hline & \multicolumn{2}{|l|}{ C5-Donations } \\
\hline & \multicolumn{2}{|l|}{ C6-Customers' health and safety } \\
\hline & \multicolumn{2}{|l|}{ C7-Qualitative service } \\
\hline \multirow{5}{*}{ P4- Environment } & \multirow[t]{2}{*}{ C1-Emissions } & Emissions of $\mathrm{CO} 2$ \\
\hline & & Emissions of NOx, SOx and PMx \\
\hline & \multirow[t]{2}{*}{ C2-Water } & $\begin{array}{l}\text { Actions over water protection, conservation and } \\
\text { management }\end{array}$ \\
\hline & & $\begin{array}{l}\text { Action related with toxic chemicals and substances } \\
\text { management (deicing chemicals) }\end{array}$ \\
\hline & \multicolumn{2}{|l|}{ C3-Energy management } \\
\hline
\end{tabular}




\subsection{Rating Approach}

Applying multi-criteria approach in this analysis, aims to evaluate the ranking of each airport in relation to the best CSR performing airport in the group. To make the different indicators compatible they are adjusted into one measurement unit (comparative scale), by defining that each criterion score will range from 0 to 1 . This normalization of the data adjusts the calculated values to the same unit of measurement in an interval range [0-1]. ' 0 ' stands for the worst performance and ' 1 ' for the best performance for each criterion and is calculated by using the equation:

$$
C_{i j}=\left[x_{i j}-\min \left(x_{i j}\right)\right] /\left[\max \left(x_{j}\right)-\min \left(x_{j}\right)\right]
$$

where:

Cij: the adjusted CSR performance value of airport enterprise $i$ on perspective $j$

xij: the CSR performance value of airport enterprise $i$ on perspective $j$

$\min (x j)$ : the minimum CSR performance value of the airport's enterprise group's scores on perspective $\mathrm{j}$

$\max (x \mathrm{j})$ : the maximum CSR performance value of the group's scores on perspective $\mathrm{j}$

For each airport enterprise $\mathrm{i}$ in the sample, the four CSR perspectives are defined to identify: (a) airport operational efficiency; (b) airport business resilience; (c) tourism market development; and (d) environmental impact. Overall performance for each airport enterprise i is the sum of the scores on the different "CSR performance ratios" presented above. For the purpose of this analysis it is assumed that all the criteria selected, affect equally the final evaluation result and an unweighted evaluation is adopted. The total score of airport enterprise $i$, can be formalized as:

$$
S_{i}=\sum c_{i j}
$$

where:

$\mathrm{Si}$ : the overall performance of airport $\mathrm{i}$ within the selected group of airports

Cij: the performance of airport enterprise $i$ on each perspective $j$

\section{Numerical Application}

\subsection{Airport Enterprises CSR Performance Evaluation Results}

The evaluation framework is applied to a sample of 15 European airports located in different countries (Table 2). To ensure comparability of the airports sample, the annual passengers accommodated are chosen to be at a level of homogeneity between 4 and 6 million pax annually.

The data derived based on the qualitative and quantitative data from airports CSR, Sustainability reports and airport official websites. Therefore, the analysis outputs provide 
evaluation scores for a group of competitive airports enterprises with similar demand characteristics and operation regulatory framework (Table 2).

Table 2. Airport enterprise CSR Performance results

\begin{tabular}{|l|c|c|c|c|c|c|}
\hline Airport / Airport Operator & Code & Employees & Community & Customers & Environment & Total \\
\hline Heathrow Airport & LHR & 0.024 & 0.016 & 0.366 & 0.785 & $\mathbf{1 . 1 9 0}$ \\
\hline Stansted Airport & STN & 0.658 & 0.508 & 0.657 & 0.785 & $\mathbf{2 . 6 0 8}$ \\
\hline Athens Airport & ATH & 0.957 & 0.672 & 0.363 & 0.785 & $\mathbf{2 . 7 7 7}$ \\
\hline Fraport / Frankfurt Airport & FPT & 1.022 & 0.781 & 1.000 & 1.000 & $\mathbf{3 . 8 0 3}$ \\
\hline $\begin{array}{l}\text { Aeroports de Paris / Charles de } \\
\text { Gaulle \& Orly Airport }\end{array}$ & ADP & & & & & \\
\hline Vienna Airport & VIE & 0.000 & 1.000 & 0.512 & 0.892 & $\mathbf{3 . 4 0 4}$ \\
\hline Schiphol Amsterdam Airport & AMS & -0.028 & -0.037 & 0.000 & 0.072 & $\mathbf{0 . 5 7 7}$ \\
\hline Geneva Airport & GVA & 0.978 & 0.330 & 0.000 & 0.360 & $\mathbf{0 . 2 5 2}$ \\
\hline Manchester Airport & MAN & 0.915 & 0.563 & 0.581 & 0.892 & $\mathbf{2 . 8 5 8}$ \\
\hline Gatwick Airport & LGW & 0.000 & 0.110 & 0.799 & 1.000 & $\mathbf{1 . 9 0 9}$ \\
\hline DAA / Dublin Airport & DAA & 0.099 & 0.000 & 0.000 & 0.504 & $\mathbf{0 . 6 0 3}$ \\
\hline TAV / Ataturk Airport & TAV & 0.893 & 0.016 & 0.366 & 0.144 & $\mathbf{1 . 4 1 9}$ \\
\hline Hamburg Airport & HAM & 0.396 & -0.036 & 0.000 & 0.000 & $\mathbf{0 . 3 6 0}$ \\
\hline Prague Airport & PRG & 0.224 & 0.110 & 0.000 & 0.360 & $\mathbf{0 . 6 9 4}$ \\
\hline $\begin{array}{l}\text { Aeroporti di Roma / Fiumicino \& } \\
\text { Ciampino Airports }\end{array}$ & ADR & 0.251 & -0.036 & 0.799 & 0.570 & $\mathbf{1 . 5 8 4}$ \\
\hline
\end{tabular}

What should be clarified about the quantitative extension of data is that they include the numerical or monetary reference of the quantitative data relating to them. More specifically, as examples can be mentioned: a) the numerical reference of gender split for the 1.1.2sub-criterion, b) economic data about the amount of money spending each airport for donations (2.1criterion), c) customers' satisfaction indexes that possible included in the 3.4 criterion and d) measurements' results that are reported about the emissions in criterion 4.1.

Through the following arachnoid diagrams about SCP (Social Comprehensiveness Performance) (Figure 2a) and ECCE (Employees-Community-Customers-Environment) performance (Figure $2 b$ ) is given an imaging capture of useful information.

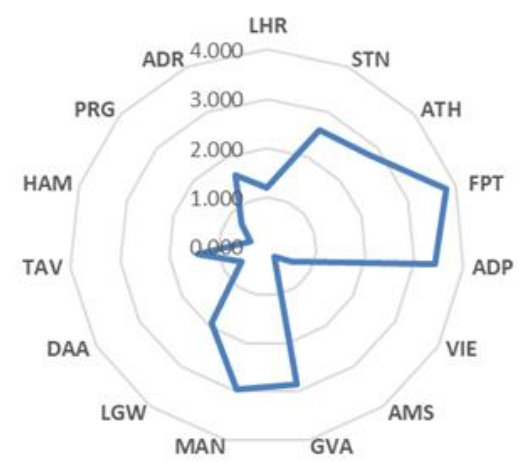

Figure 2a. SCP performance

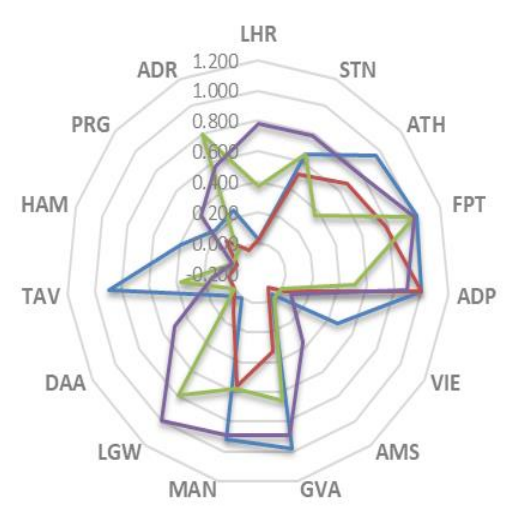

Figure 2b. ECCE performance

Information can be extracted by this SCP and ECCE depiction for each airport is: i) the SCP for each airport ii) their performance in each category of stakeholders, iii) how balanced are 
the four stakeholders and iv) airports' ECCE orientation, depending by in which category are most strengthen.

What can be extracted as a general conclusion by this depiction is that airports are basically in detail reporting their environmental performance more than any other stakeholder-dimension. These findings apply on the reason that the factor "Environment" has a significant importance for airports' responsible role in local communities. Despite the advantages that derived by the existence of an airport in the local community, there are inevitable disadvantages that generate negative impacts on the environment. Consequently, the challenge for airports' operators will be to balance the social and economic benefits of an airport to a region or city, with the disturbance on the environment and on the human health (Dimitriou et al., 2020).

Moreover, it is ascertained that airports with high SCP have a more balanced performance in their stakeholders than others with low performance. Thus, airports that pass over the average score of at least three of the stakeholders are classified at the higher social performed airports of the sample (e.g. Frankfurt airport, Aeroports de Paris, Manchester airport, Athens airport, Stansted airport and Geneva airport). In contrast Heathrow airport results highlight that, it exhibits low performance because of its decision to report brief CSR reports and not extended and detailed as other airports of the sample.

\subsection{Stakeholder Orientation and CSR Performance}

Based on actions' evaluation that exacted by airports' CSR and Sustainability reporting, actions that referred to CSR and sustainability weighted, by taking into consideration the qualitative and quantitative comprehensiveness of the 4 pillars (stakeholders) of analysis (Employees, Community, Customers and Environment). This data analysis led to four (4) "stakeholder-oriented" CSR strategies:

- CSR strategy 1: Holistic "stakeholder-oriented" CSR strategy

In this strategy, the airports classified here, have a balanced performance among all stakeholders. All these airports have at least on three of their stakeholders an over the average performance. That means that they give as much as possible equally importance to all their stakeholders' expectations. Alternative, we could also call this holistic stakeholder CSR strategy as "Citizenship Strategy" (Freeman, R. E., \& McVea J. , 2001).

- CSR strategy 2: CSR strategy oriented to Environment (Em) and Community (Co)

Airports belong to this kind of strategy exhibit over the average performance on "Environment" having at the same time their lowest performance on "Employees".

- CSR strategy 3: CSR strategy oriented to Employees (Em) and Customers $(\mathrm{Cu})$

The airport that classified in this strategy has a clear orientation in employees' CSR reporting. This evidence gives an employees' conscious character in this airport's CSR strategy. 
- CSR strategy 4: Low-comprehensive "stakeholder-oriented" CSR strategy

All these airports that belong in this strategy have at least on three of their stakeholders an under the average performance. That means that their totally social comprehensiveness performance is low and Corporate Social Responsibility is not widely applicable in their business strategy or it is not reported in an appreciable extent. However, in our methodological analysis, it is assumed that not reporting about CSR issues equated to not aware and concern about them. However, it is noted that these airports have their higher performance by majority on "Environment

In the following diagram (Figure 4), four sections (A, B, C \& D) identified, each of these represents one of the four different CSR strategies (Figure 5). The option of dual comparative analysis of stakeholders in order to identify the "stakeholder-oriented" CSR strategies, as it is shown on the following diagram (Figure 4), based on the view that: i) Community and Environment describes the aspect of Society and ii) Employees and Customers the aspect of People.

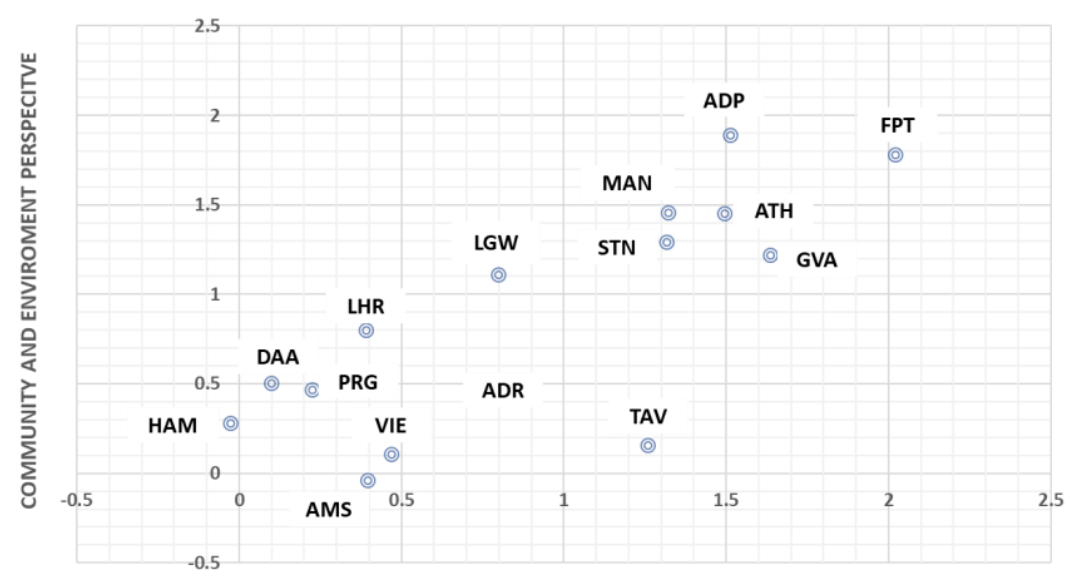

EMPLOYEES AND CUSTOMERS PERSPECTIVE

Figure 3. Performance results based on stakeholder orientation strategy

\subsection{CSR Performance Results Analysis}

The significant role of airports on regional economy has been well recognized in many researches; airports bring significant social benefits and in many cases they are thought to be the single largest generator of economic activity in the regions they serve (Air Transport Action Group, 2008). Additionally, many airports highlight that European regions with airports and significant air services have a better social and economic development with lower unemployment, higher productivity and higher income per-capita, compared with regions without airports (ACI Europe, 2004). For this reason, a simple comparative analysis will be presented, related to the SCP of airports with regional GDP (PPP) per capita and in order to describe how airports' SCP associated with this factor that depict an aspect of regional economic wealth. Additionally, an analysis of airports is presented in a comparison with airports passenger traffic as to reach at some comments about this relationship.

According to the diagram (Figure 4) that depicts the relationship between SCP and regional 


\section{Macrothink}

GDP (PPP), the four sections that formed demonstrate common characteristics about the included airports.

A section: Airports included in this section, performed over 50\% in the SCP index. In addition, they represent a positive relation between SCP and regional GDP, which means that these airports' high SCP performance harmonized with the regional economic wealth.

$\mathrm{C}$ and D section: Airports in the section that consisted from $\mathrm{C}$ and $\mathrm{D}$ section do not appear to have significant range among their regional GDP. Nevertheless, there is a wide range of SCP in these two sections where belong from the highest performer (FPT) to the lowest performer (AMS).

B section: Airports that belong in this section are some of these that although located in areas that present a high level of regional GDP (PPP) per capita, that are not in the line of SCP. It would be expected that these airports would have shown better results in the SCP performance.

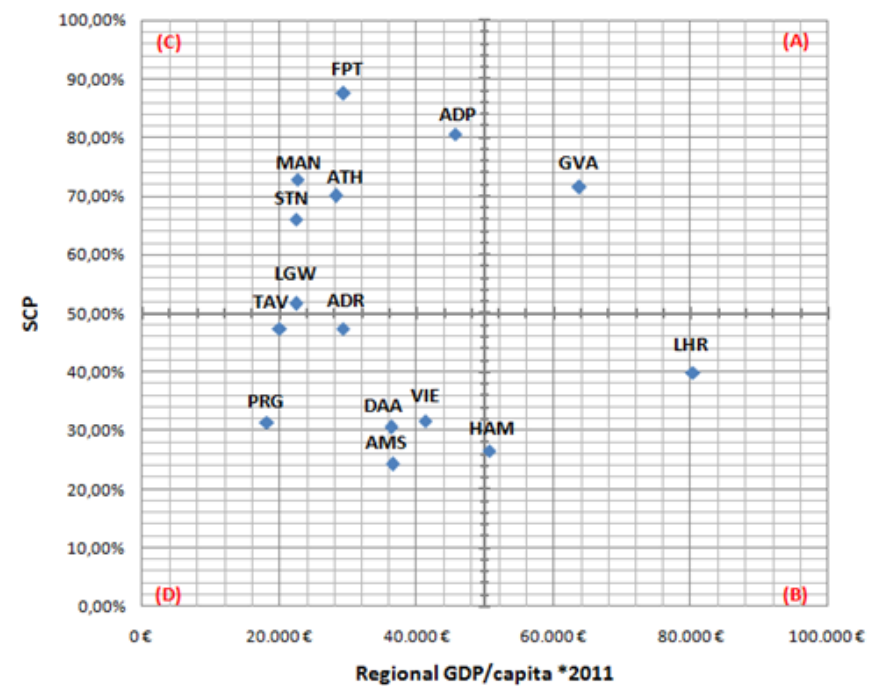

Figure 4. SCP / Regional GDP (PPP) per capita

With data collected about airports' traffic in 2013, the following diagram (Figure 7) represents how SCP associated with the passenger traffic. According to this, four sections identified, helping to lead on some comments about this relationship.

$\mathrm{B}$ and D section: In this section belong airports that although positioned in the traffic category of about $10 \mathrm{M}$ to $20 \mathrm{M}$ PAX, they form two discrete categories of Social Comprehensiveness performance, the "over-the-average" (65\% to $75 \%)$ performed and the "below-the-average" performed (25\% to $35 \%)$.

A and C section: Airports of these two sections belong at the over 40M PAX category. What is considerable here is that there is a wide range of SCP results, between $90 \%$ to $20 \%$. This fact leads to the conclusion that airports with high performance in traffic are not implied to have high SCP, even though it would be expected.

It should be also considered that the middle-positioned airports on SCP (LGW, ADR and TAV) 
belong at the category of $35 \mathrm{M}$ to 55M PAX.

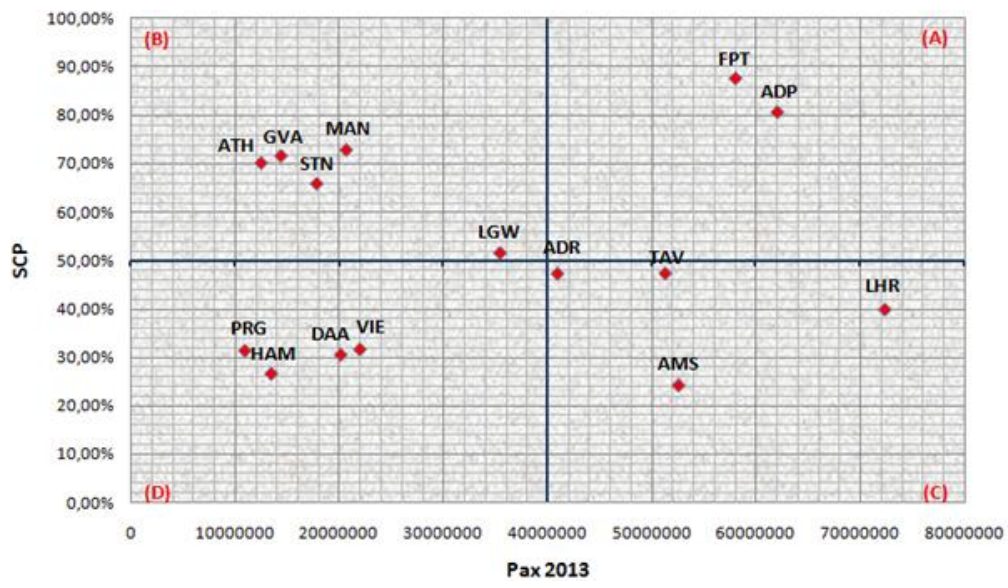

Figure 5. SCP / Passengers traffic

With data collected about airports' traffic in 2013, the following diagram (Figure 7) represents how SCP associated with the passenger traffic. According to this, four sections identified, helping to lead on some comments about this relationship.

$\mathrm{B}$ and D section: In this section belong airports that although positioned in the traffic category of about $10 \mathrm{M}$ to $20 \mathrm{M}$ PAX, they form two discrete categories of Social Comprehensiveness performance, the "over-the-average" (65\% to $75 \%)$ performed and the "below-the-average" performed ( $25 \%$ to $35 \%)$.

A and $\mathrm{C}$ section: Airports of these two sections belong at the over 40M PAX category. What is considerable here is that there is a wide range of SCP results, between $90 \%$ to $20 \%$. This fact leads to the conclusion that airports with high performance in traffic are not implied to have high SCP, even though it would be expected.

It should be also considered that the middle-positioned airports on SCP (LGW, ADR and TAV) belong at the category of $35 \mathrm{M}$ to 55M PAX.

\section{Conclusion}

Based on the CSR and Sustainability indicators, an evaluation review of a sample of 15 of the busiest European airports presented. By identifying the key stakeholders and the reported actions related to CSR values, the assessment framework based on benchmarking adopted to categorize these actions and evaluate each airport's comprehensiveness in reporting quantitative data about CSR actions. The results output of this evaluation framework (ECCE Framework) based on reference airports' key stakeholders (Employees, Community, Customers, Environment) highlight the comprehensiveness of airports sustainable development based on environmental issues, highlighting that air transport enterprises need an efficient sustainability management framework to effectively manage economic, environmental and social risks to achieve their corporate sustainability objectives, and to meet their stakeholders' demands.

Output of the CSR driven analysis framework and stakeholder theory support the balanced satisfaction of stakeholder's expectations is that airports extensively and analytically report 
mainly the environmental aspect of CSR. As it is noted, there is significant deficit in comprehensive reporting on CSR issues because it is in discretion of airports to do it, without a legal obligation. Due to reporting comprehensiveness affects airports' Social Comprehensiveness Performance, in this analysis considered that not reporting or limited reporting, related to not aware and concern about CSR issues (an exception is the Heathrow airport). Therefore, CSR reports based on GRI guidelines highlighted that airports demonstrate better performance in SCP index than these that do not applied them.

The papers' conceptual analysis and results enhances CSV's potential to generate sustainable development and suggests the way forward for airport enterprises whose executives support innovation and sustainable development is to practice organizational innovation, and balance of stakeholders expectations for both environmental, financial and social aspects.

The assessment framework is a valuable tool for evaluating quantitative comprehensiveness of CSR and CVS aspects considering stakeholders' perspectives as decision makers, managers and stakeholders involved in management process issues. By identifying their CSR strategies orientation, they could evaluate how balanced in their stakeholders' social obligations are and redefine their strategies for being more efficient in corporate responsible issues can be. Recommendation for further research should apply the benchmarking analysis to a larger sample of airports and enhance the CVS potential for airport enterprise efficient management and sustainable development. In addition, a further research analysis should be addresses in applying the benchmarking analysis in other sectors of transportation, in order to promote vital key messages from a holistic view for stakeholders' positioning on corporate socially responsible issues of transport sector.

The proposed methodological framework enables decision makers, stakeholders and authorities to compare the performance of different airports sustainable development strategies based on CSR comprehensiveness in a country or airport enteprises with similar characteristics in different countries and highlight the level of contribution of airports enterprise towards sustainable development. Overall novelty of the paper is that the benchmarking analysis may enable decision makers to distinguish between the weaknesses and the potential of airport enterprises management, in order to set action priorities in the management of the enterprise towards sustainable development.

\section{References}

Aguinis, H. A. G. (2012). What we know and don't know about corporate social responsibility a review and research agenda, J. Manag., 38(4), 932-968.

Aarseth, W. A., \& Rolstadås, B. A. (2011). Key factors for management of global projects: A case study. International Journal of Transitions and Innovation Systems, 1(4), 326-345.

ACI, CANSO, IATA, ICAO, ICCAIA, (2019). "Aviation Benefits Report 2019". pp. 6-9., ttps://www.icao.int/sustainability/Documents/AVIATION-BENEFITS-2019-web.pdf.

Bocquet, R., Le Bas, C., Mothe, C., \& Poussing, N. (2017). CSR, innovation, and firm performance in sluggish growth contexts: a firm-level empirical analysis. J. Bus. Ethics, 146(2017), 241-254. 
Dimitriou, D., Voskaki, A., \& Sartzetaki, M. (2014). Airports environmental management: Results from the evaluation of European airports environmental plans. International Journal of Information Systems and Supply Chain Management (IJISSCM), 7(1), 1-14.

Dimitriou, D. (2018). Evaluation of tourist airports productivity towards tourism development. International Journal of Cogent Business and Management, 5(1464378), 1-15.

Dimitriou, D., Sartzetaki, M., Lintzerakou, S. (2019). Management Directions towards Social Responsibility in Special Population Groups by Airport Enterprises: The Case of Autism, International Journal of Economics and Management Engineering, 13(9), 1251-1254.

Dimitriou, D., \& Sartzetaki, M. (2018). Assessing air transport socioeconomic footprint, International Journal of Transportation Science and Technology, 7(4), 283-290.

Dimitriou, D., \& Sartzetaki, M. (2016). Sustainable Development Variables to Assess Transport Infrastructure in Remote Destinations, International Journal of Urban and Civil Engineering, 10(10), 1343-1350.

Dimitriou, D., \& Sartzetaki, M. et al. (2020). Chapter 1: Mobility as A Service: CONCEPT, OBJECTIVES, ACTORS, MODELS AND DEVELOPMENT, Book title: Mobility as a Service, Transport Trends and Economics 2018-2019, United Nations, UNECE, ISBN: 978-92-1-117238-6, pp. 9-13.

Dimitriou, D., \& Sartzetaki, M. (2019). Chapter title: Social dimension of aviation on sustainable development, Book title: Sustainable aviation -Greening the Flightpath, Palgrave Macmillan, 173-191.

Desai V. M. (2018). Collaborative stakeholder engagement: An integration between theories of organizational legitimacy and learning. Academy of Management Journal, 61(1), 220-244.

Galbreath, J. (2006). Corporate social responsibility strategy: strategic options, global considerations. Corporate Governance. The international journal of business in society, 6(2), 175-187.

De Gooyert, V., Rouwette, E., Van Kranenburg, H., \& Freeman, E. (2017). Reviewing the role of stakeholders in operational research: A stakeholder theory perspective. European Journal of Operational Research, 262(2), 402-410.

Madueno, J. H., Jorge, M. L., Conesa, I. M., \& Martínez-Martínez, D. (2016). Relationship between corporate social responsibility and competitive performance in Spanish SMEs: Empirical evidence from a stakeholders' perspective. BRQ Business Research Quarterly, 19(1), 55-72.

Eskerod, P., Huemann, M., \& Ringhofer, C. (2015). Stakeholder Inclusiveness: Enriching Project Management with General Stakeholder Theory1. Project Management Journal, 46(6), 42-53.

Jamali, D. (2008). A stakeholder approach to corporate social responsibility: A fresh perspective into theory and practice. Journal of business ethics, 82(1), 213-231.

Klewitz, J., \& Hansen, E. G. (2014). Sustainability-oriented innovation of SMEs: a systematic review. Journal of cleaner production, 65, 57-75.

Koç, S., \& Durmaz, V. (2015). Airport corporate sustainability: An analysis of indicators 
reported in the sustainability practices. Procedia-Social and Behavioral Sciences, 181, 158-170.

Li, J., Xia, J., Zajac, E. J. (2018). On the duality of political and economic stakeholder influence on firm innovation performance: Theory and evidence from Chinese firms. Strategic Management Journal, 39(1), 193-216.

Lo, S. F., \&Sheu, H. J. (2007). Is Corporate Sustainability a Value an increasing Strategy for Business? Corporate Governance: An International Review, 15(2), 345-358.

Longo, M., Mura, M., \& Bonoli, A. (2005). Corporate social responsibility and corporate performance: the case of Italian SMEs. Corporate Governance. The international journal of business in society, 5(4), 28-42.

Montiel, I. (2008). Corporate social responsibility and corporate sustainability separate pasts, common futures. Organization \& Environment, 21(3), 245-269.

Marin, L., Martín, P. J., \& Rubio, A. (2017). Doing good and different! The mediation effect of innovation and investment on the influence of CSR on competitiveness. Corporate Social Responsibility and Environmental Management, 24(2), 159-171.

Neumeier, S. (2017). Social innovation in rural development: identifying the key factors of success. The geographical journal, 183(1), 34-46.

Naor, M., Druehl, C., \& Bernardes, E. S. (2018). Servitized business model innovation for sustainable transportation: Case study of failure to bridge the design-implementation gap. Journal of Cleaner Production, 170, 1219-1230.

Porter, M. E., \& Kramer, M. R. (2011). Creating shared value: how to reinvent capitalism and unleash a wave of innovation and growth. Harv. Bus. Rev., 89(1), 62-77.

Pedersen, E. R. G., Rosati, F., Lauesen, L. M., \& Farsang, A. (2017). What is in a business case? Business cases as a tool-in-use for promoting water management practices in the food sector. Journal of Cleaner Production, 162, 1048-1060.

Sartzetaki, M. (2019). Airport enterprises management performance evaluation towards innovation and sustainable development. The International Journal of Business Management and Technology, 3(4), 108-114.

Sartzetaki, M. (2019). Value Based Management Analysis Framework Towards Transport Enterprises Resilience, International Journal of Economics, Business and Management Research, 3(6), 82-96.

Sartzetaki, M., Asprouli, V., Dimitriou, D., \& Konstantinidis, T. (2019). Assessing health and safety risks in regional airport enterprises, International Journal of Science and Research (IJSR), 8(9), 544-547.

Vveinhardt, J. R., Andriukaitiene, L. M. C. (2014). Social capital as a cause and consequence of corporate social responsibility. Transform. Bus. Econ., 13(2014), 483-505.

Zhao, Z., Meng, F., He, Y., \& Gu, Z. (2019). The influence of corporate social responsibility on competitive advantage with multiple mediations from social capital and dynamic capabilities. Sustainability, 11(1), 218. 


\section{Copyright Disclaimer}

Copyright for this article is retained by the author(s), with first publication rights granted to the journal.

This is an open-access article distributed under the terms and conditions of the Creative Commons Attribution license (http://creativecommons.org/licenses/by/4.0/). 